\title{
Boredom and Social Deviant Behavior: An Empirical Study
}

\author{
Nicola Malizia \\ University of Enna “Kore”, Enna, Italy \\ Email: nicola.malizia@unikore.it
}

How to cite this paper: Malizia, N. (2018) Boredom and Social Deviant Behavior: An Empirical Study. Advances in Applied Sociology, 8, 174-187.

https://doi.org/10.4236/aasoci.2018.82010

Received: December 13, 2017

Accepted: February 10, 2018

Published: February 13, 2018

Copyright $\odot 2018$ by author and Scientific Research Publishing Inc. This work is licensed under the Creative Commons Attribution International License (CC BY 4.0).

http://creativecommons.org/licenses/by/4.0/

\section{c) (i) Open Access}

\begin{abstract}
The purpose of this paper was the analysis of the relationship between boredom and deviance behavior; this is a field not completely explored by the sociology of deviance, despite the increase in alarm due to the increase in: deviant behavior by young people and crimes committed by groups. After a brief presentation of the most important contribution in literature, to deepen this issue, we use data collected from a survey using as principal instrument, the Boredom Proneness Scale, BPS, (Farmer \& Sundberg, 1986) to identify the possible forms of prevention to be adopted in family, social and institutional context, in order to not compromise, immediately or in the long term, social, physical and psychological young person well-being. To test the evidence, it was decided to implement a model, in order to describe and analyze empirical phenomena, introducing a statistical relationship, since it is not possible to know an exact relationship between variables. The model results allow to observe a direct relationship between the BPS and variables analyzed.
\end{abstract}

\section{Keywords}

Boredom, BPS, Deviant Behavior, Deviance, Society

\section{Introduction}

The relationship between boredom and deviance is a field not completely explored by the sociology of deviance, despite the increase in alarm due to the increase in: deviant behavior by young people and crimes committed by groups. To deepen this issue is necessary to identify the possible forms of prevention to be adopted in family, social and institutional context, in order to not compromise, immediately or in the long term, social, physical and psychological young person well-being. When boredom determines the passage to the deviant act, it 
is necessary to analyze the inner (personal) and external (social factors) forces that have driven and determined this behavior.

On the relationship boredom/youth deviance, the theoretical reflections of sociologists have defined, over time, the effects and social conditioning in terms of reactivity in: voluntary abandonment of institutional paths, the lack of acceptance of social configuration, the push towards social changes, the need to reach new goals or take risks, the presence of social disintegration that create discomfort, impotence, inactivity, which can also turn into boredom. For this reason, we expected that daytime activities and boredom proneness scores could be significant predictors of youth deviance. Boredom can be the result of a frustration of primary needs, responses and absence of certainties. Leisure time could turn into boredom when personal skills and real opportunities for recreation are lacking, such as to cause the deviant activities by subject. It should be noted that these behaviors are not the result of environmental and social conditioning, but, as stated by Matza, are closely linked to the will and self-determination of the subject. The aim of the research is to highlight the relationship between boredom and deviance in society, in order to understand, also, the dynamics and the different behaviors of the associates, which could be useful for future and possible interventions in social and institutional sphere.

\section{Literature Review}

Durkheim uses the term anomie also in reference to the morally deregulated condition, highlighting that the subjects may have little control over their behavior (Durkheim, 2008). Deviance and crime, which are expressions of subjective behavior, providing immediate gratification for needs and desires, bringing out of boredom, determined by the repetition of tasks and situations and pushing an insatiable need to look for adventures dangerous, new and electrifying, often deviant.

In this vision, crime is the set of acts of force or fraud undertaken by hobby and personal interests; from this view, it follows that the types of crime can be described, through the combination of two elements: the opportunity to engage criminal acts and low self-control (Hirschi \& Gottfredson, 1993). Boredom represents an emotional state that arises from the absence of meaning of a situation or activity by a subject, which tends to turn into a restless and irritating sensation that needs to be replaced (Barbalet, 1999). Boredom can also be linked to the lack of involvement in daily events; senselessness and lack of momentum may also represent factors that encourage the search for meaning, which can, however, present a risk, deviance, conflict (Brissett \& Snow, 1993). If in the free time prevails boredom and lack of personal skill and opportunities for recreation, some young people can adopt deviant behavior (such as the use of drugs, alcohol, gambling) or more specifically criminal: stealing, vandalizing, violent sexual orientation, etc. (Iso-Ahola \& Crowley, 1991). Youth boredom could also be the result of the non-knowability and accessibility of activities that 
constitute real leisure or entertainment (Stebbins, 2002). According to Thomas, the non-fulfillment of primary needs, such as safety, new experiences, gain recognition and have an activity that give the person a sense of contribution, or the conduct of an interest-free life, could lead young people to adopt deviant behavior (Volkart, 1951). Wilmott studied, e.g. the London working class; analyzing the relationship between young and crimes, he attempted to identify a subculture reference, but concluded that crimes were related primary to boredom (Wilmott, 1966). In young people, a proper management of free time could be a decisive factor in removing deviant interests; in this perspective, the involvement of teenagers in sports activities to dissuade them from delinquency and other deviations could be particularly important (Schafer, 1969). Some researches on sports and athletes have shown a significant reduction in the recruitment of deviant behavior than non-athletes (Segrave \& Hastad, 1984). Religion, in addition to offering spiritual comfort, can also encourage respectability and conformity to social constructs (Weber, 1920).

According to Wilson and Herrnstein, individual reactivity to social inactivity could be explained starting from the biosocial theory of criminal behavior that mainly affects young people: for the authors, crime is caused by a combination of both biological and social functions; individual biological differences make some people prone to commit crimes than others. They assert that crime is a manifestation of the same human nature that produces acts of greatness. Authors emphasize the importance of familial and political associations to the development of man's capacity to act freely and independently. Similarly, they argue that primary cause of crime is low intelligence, which they also see as biologically determined (Wilson \& Herrnstein, 1998). Since the first half of the 50s, some researchers claimed that low stimuli evoked "boredom", similar to hunger or thirst, that the sensory experience of variety could reduce. For this reason, curiosity and exploratory behavior are aimed to reduce boredom (Berlyne, 1950; Myers \& Miller, 1954; White, 1959). In the sociological perspective, the relationship between boredom and deviance is mostly attributed to aspects and consequences of different social and dynamic factors that can affect personal sphere and reactivity of the individual: the absence of adequate political channels to express the young people deprivations (Lea \& Young, 1984); in a similar way, according to the fracture theory between social and cultural structure (Merton, 1938), deviance could be considered as abandonment of institutional paths, or as a non-acceptance of the social structure, assuming the character of creativity, innovation pushing social changes. Boredom could also be the product of the tensions that derive from social disintegration and which create a discomfort common to many young people; Cohen's suggestion that members of delinquent subcultures consciously invert the norms and values of mainstream society has been criticized. Author argue that deviance is the result of individuals conforming to the values and norms of a social group to which they belong, if you belong to a social group whose norms differ from those of the main society then you 
will become a deviant (Cohen, 1955). In these subcultures people commit nonutilitarian crimes, deviant behavior becomes something that reward the individual with respect and reinforce the group identity (Cloward \& Ohlin, 1960; Cohen, 1972). Hence the importance of the social bond underlined in the control theory (Hirschi, 1969), according to, if the young person has a stronger connection with the "gang" than with parents or adults in general, he is more likely to becoming delinquent. Merton modifies Durkheim's concept of anomy to establish what he describes as the theory of deformation: the hypothesis (Mason \& Wilson, 1988; Mason, 1996), is that individuals remain law-abiding and united while having access to means to pursue objectives (Merton, 1938, 1967, 1968), and affirms that society achieves its unity through the possession of certain values by its members; however, when there is a discrepancy between aspirations and expectations, it produce tension and/or frustration which results in the breaking of cultural norms that may lead to deviate (Merton, 1968). Through his theory of "delinquency drift" Matza explains how he thinks young people within a subculture can break the values of society without really recognizing that they are doing. Rather than representing crime with the usual method, Matza's aim (Clinard \& Meier, 1995) was to develop a judgment on deviance, exploring it from the point of view of deviant, to understand the view of the offender and interpret the world as it appears to him. According to this theory (Trojanowicz \& Morash, 1992), environmental factors do not induce an individual to become a delinquent. Matza argues that during this period of drift, the constraining bonds of society are loosened and so adolescents become more susceptible to suggestions of deviant acts by the peer group. Committing a delinquent act may then represent an attempt to demonstrate control over their lives, to exercise choice (Matza, 1964). In this context, therefore emerges the subject individuality that is permeated by forces, stimuli, apathy, intolerances culminating in the reaction. According to Matza (Gibbons \& Krohn, 1991) individuals are to a considerable extent constrained or influenced by social and environmental forces, but at the same time, they are reactive subject able to exercise a certain degree of freedom or choice on their behavior; when a young falls into deviance he is still influenced by the morality of conventional society. To reduce the guilt that most people will develop before committing a crime, individuals will use a method known as neutralization (Matza, 1964). In social processes, the "meaning" is particularly important: an absence of meaning in an activity or a circumstance leads to a boredom experience and push the actor to search meaning, with the assumption of atypical social practices, including risk taking. Meaning directs and defines action; pervades core categories for sociology as "culture", "value", "norm", and so on. The "meaning" typically refers to a set of symbolic objects that identify or create significant social realities. Meaning, therefore, is not an intrinsic property of objects but of the relationships of people who come into contact with such objects. Since certain meanings provide context, reference, purpose to actions, social life itself would become unrealizable without the qual- 
ity of meaning (Garfinkel, 1967; Luhmann, 1984). If the meaning becomes central to social processes, it should be noted that it is never a sufficient condition and may even be absent. Social mobility, for example, is a process that does not require meaning, therefore, boredom would appear as an emotional protection and a defense against the absence of meaning. Even the alienation theory describes boredom as its central experiential component (Marx, 2004 [1844]). The senselessness and boredom of alienated labor (Seeman, 1959), as well as the absence of intrinsically rewarding activity, generate meaninglessness as self-alienation. The difference between the habitual action on one side, and the boring one, on the other, is well identified by Heller: until the repetitive action is a means to an end, involvement is minimal and without any feeling of boredom. When the repetition loses its function or its purpose, a strong and direct involvement of negative type arises, that is boredom; this negative involvement of boredom is experienced as anxiety. It would therefore be erroneous to deduce from the Heller's formulation that boredom arises only from under-stimulation. The loss of purpose can result from over-stimulation, through which social meanings are weakened (Stein \& Heller, 1979). The search for novelty (Durkheim, 1962 [1893]) and the intensity of urban life (Simmel, 1996) are both examples of excessive stimuli that lead to boredom. The distinction between boredom and depression is significant, although both register an absence of interest in activities and circumstances: boredom is a restless feeling of dissatisfaction with such state and results from a loss of purpose; depression is characterized instead by anxiety, fatigue, a loss of consideration, position or status (Kemper, 1978). From this, it follows that boredom is more typically turned outside, while depression concerns the inner self, the commitments and the environment. Reactivity or not to boredom, on the other hand, is the propensity to take risks, as a set of characteristics of planning habits and lifestyle (Giddens, 1991). Further research has highlighted differences in experiences of boredom between male and female: males tend to be more competitive both in sports and occupations, more involved in adventurous and risky activities, but also more prone to boredom if they did not belong to that category of subjects; females, considering that society has moved towards equality, are crossing gender boundaries by performing activities that are usually considered masculine, starting to experience boredom too; this would explain the increase in their deviant behavior (Vodanovich \& Kass, 1990a). Zuckerman's Sensation Seeking Theory fully recognizes the boredom concept. Using Eysenck's theory of extroversion, which incorporates sociability and impulsivity (Cook, 1993), Zuckerman defines the sensation seeking as a kind of "non-inhibited, non-conforming, impulsive, dominant" extroversion, composed of distinct factors: thrill, search for adventure, search for experience, disinhibition and susceptibility to boredom (Ragheb \& Merydith, 2001; Zuckerman, Eysenck, \& Eysenck, 1978). Disinhibitors or “extroverted sensation seekers" will seek sensations through social stimulation and disinhibitory behavior (usually associated with the use of alcohol and drugs), 
while individuals who are prone to boredom will avoid boring people and repetitive activities (Zuckerman, Eysenck, \& Eysenck, 1978). Zuckerman et al. recognize that since some extroverts and sensation seekers appear to be "chronically under-excited" (Seamon \& Kenrick, 1994), the search for sensations is a general trait that depends from his expression and range of environmental possibilities (Zuckerman, Eysenck, \& Eysenck, 1978): therefore, most of sensation seeker are looking for variety, novelty and challenges in the environment (Iso-Ahola \& Crowley, 1991; Gordon \& Caltabiano, 1996). However, if the environment does not satisfy feelings seekers, "people can be driven to seek fulfillment through crime" (Gordon \& Caltabiano, 1996). In this sense, Zuckerman et al. points out that people who are involved in criminal activities "are not driven by peers or compulsive neurotic needs", but rather are motivated by the need for variety of stimuli to reach their optimal level of harmony. According to Caffray and Schneider, most of the theories implicitly or explicitly suggest that young people are motivated by their desire to improve or avoid particular emotional states. Consequently, since the need of excitement includes positive effects and lack of boredom, the research involving sensation has shown that this construct is important in predicting the behavior of young people, especially involvement in crime and minor violations (Caffray \& Schneider, 2000). While sensation seeking increases from childhood to adolescence (Zuckerman, Eysenck, \& Eysenck, 1978; Baldwin, 1985), the search for a feeling decrease with maturity, favoring the exit of young people from crime. In the "Strain Theory" (Agnew, 1992), the central idea of deformation theory is that people who suffer tensions, stress, moral flattening, boredom, become anxious or upset and can commit anti-social acts. One of the key principles of this theory is emotion as a motivator of crime. "Consumer technology" has also contributed to the significant increase of boredom: society overloaded with stimuli and irrelevant information that have significantly contributed to a general desensitization, where boredom plays a defensive function as a barrier (Klapp, 1986; Brissett \& Snow, 1993). Others authors, like Caliman, take Maslow's "theory of human needs" as a starting point, partly because it is used in sociological research of Inglehart and other sociologists. This theory divides needs into two types: materialists (sustenance and security), post-materialists (belonging, esteem and self-realization-freedom). In fact, the different needs depending on the socio- economic-cultural condition and on the basis of them also changes the type of social hardship, especially juvenile (Caliman, 1997).

\section{Method}

Questionnaires may be used to collect regular or infrequent routine and data for specialized studies. The data analyzed in this survey was drawn from a stratified random sample. It is obtained by separating the population into mutually exclusive sets and then drawing simple random samples from each stratum. After the population has been stratified, we used simple random sampling to generate the 
complete sample. Response Rate (i.e. the proportion of all people selected who complete the survey) is a key survey parameter and helps in the understanding the validity of the survey and sources of nonresponse error; in order to maximize return rates, questionnaires have designed to be as simple and clear as possible (Edwards \& Cantor, 1991; Sudman et al., 2000), with targeted sections and questions. Participants in the present study were 456 . They were provided with an informed consent document which they signed and were told that participation was voluntarily. Respondents completed a five-page questionnaire that was accompanied by a cover letter indicating that the questionnaire was completely anonymous and voluntary. The participants were instructed to complete a survey that included three sections: a brief demographic questionnaire, the Boredom Proneness Scale (BPS, Farmer \& Sundberg, 1986) and specific questions about lifestyle and possible deviant behavior.

The first section of the instrument requested demographic information. The survey contained a brief demographics questionnaire in which the participants reported: their age, gender, ethnicity, education level (years in school and Educational attainment), religious orientations, professional or employment status, household annual income and geographic location. Data collected on this aspect could be essentially to capture nonlinear effects.

The Boredom Proneness Scale (BPS) was developed by Farmer \& Sundberg (1986) and consists of 28 items designed originally in a true/false form. The internal consistency of the original BPS has showed by a lot of authors such as Ahmed (1990), Blunt \& Pychyl (1998), Gana \& Akremi (1998). However, the form used in this study was the 7-point Likert that has yielded coefficient alphas from 0.79 to 0.84 across numerous studies (Vodanovich, Wallace, \& Kass, 2005; Harris, 2000; Seib \& Vodanovich, 1998; Wink \& Donahue, 1997); the authors have employed this modification of the instrument to increase the sensitivity of measurement. The range of BPS score was from 28 to 196, where a high or low score suggests a greater boredom proneness. According to Vodanovich \& Kass (1990b) approach, the 28 items of the BPS were factored into five areas: external stimulation, internal stimulation, perception of time, constraints and affective response. Data analysis plan uses a set of independent variables to predict participants' group to provide classification rates and driver factor of boredom.

The third section asked for self-descriptions on additional items, using a 7 -point scale ranging from 1 (strongly disagree) to 7 (strongly agree). The purpose of this section was the analysis of boredom on social deviant behavior. Five of the items in these sections was related to boredom, boredom proneness, or both, but were not derived from specific items on the Boredom Proneness Scale; ten questions are designed to understand the assumption of any deviant behavior by participants. The last five questions were aimed to understanding habits, routines and lifestyle. The closed-ended questions, which give a possibility to equally interpret the answers of the respondents, were used in the questionnaire, on the basis of which, the comparative analysis can be carried out. The attitude 
scale was presented in the questionnaire and the respondents were asked to indicate their extent of agreement with various statements described on a 7-point Likert scale ( $1=$ strongly disagree, $7=$ strongly agree). The selected significance level $\alpha$ is equal to 0.05 . Thus, the correlation coefficient is considered statistically significant when $p<0.05$. This scale had good internal consistency $(\alpha=0.86)$.

The participants were given unlimited time to complete the survey (though they generally reported that it took approximately 25 to 30 minutes to complete all three sections).

\section{Results}

The participants' identities were anonymous and all data was stored on a password protected computer. Their ages ranged from 16 to 41 years, with a mean of 21.3 years and a median of 22 years. The majority of the respondents were European $(\mathrm{n}=401,87.94 \%)$, with $(\mathrm{n}=45,26 \%)$ Asians, $20(4.39 \%)$ African 33 (7.24\%) and 2 of other geographical origin. A majority (75\%) of the participants were undergraduates; 25\% were graduate students. Participants were from a European background with the exceptions of 21 people that declare a different cultural background. From the 456 participants in the sample only 373 provided a usable data, showing as random sampling appears to be associated with a higher response rate $(81.73 \%)$. The final sample included 224 women $(60.05 \%)$. Men were about 0.9 years older than women on average ( $p$-value $<0.05)$. Performance was assessed in two different ways. The first one, performance (correct) was assessed as the number of items participants completed correctly. Incomplete or incorrect items did not count toward the total highlight above; second, performance (error) was assessed by subtracting the total number of items correct from the total number attempted. Performance (correct) scores ranged from 28 to 196 , with an average of 72.61 ( $S D=28.63$ ). Errors ranged from 0 to 27 , with an average of $1.27(\mathrm{SD}=2.81)$. A large proportion of women and men had never been married (93\%). About the $85 \%$ of the sample live constantly in Italy. Just over half the sample had a primary education and lived in city between 50,000 and 250,000 inhabitants.

The first phase of our work uses quantitative data from the BPS as part of the principal survey instrument employed, in combination with qualitative data obtained primarily from the first and third section of questionnaire, to provide insight as the characteristics of boredom proneness contribute to social deviancy behavior. Data from the surveys was entered into MathLab R2015a for statistical analysis including the calculation of Spearman's correlations coefficient, because this coefficient is more robust to outliers than other measure. The coefficient is 0.77 showing that there is strongly correlation between the BPS score and social deviancies behaviour; it is therefore show that the instrument used proves to be particularly useful for research purposes. The subjects were divided into 4 age groups by the generation of 4 age quartiles. The mean values of BPS scores were determined for each age quartile for subsequent inferential analysis (e.g. one- 
way analysis of variance with Least Significant Difference, LSD, post-hoc comparisons). A LSD analysis showed significant differences in BPS scores between the 16 - 18 (the first quartile) and 25+ age groups (the fourth quartile) ( $\mathrm{MD}=$ $15.73, p<0.05$ ). Regarding BPS scores, the first 3 age quartiles (up to the $75^{\text {th }}$ percentile in age) had significantly higher BPS scores, then the oldest age quartile (above $75 \mathrm{ft}$ percentile in age). It was also determined that BPS scores were the highest in the younger age groups compared with the older. People with higher Boredom Proneness scores reported that they were more often angry, frustrated, less likely to believe that could ever be fun and use the social deviancies behavior to escape from boredom. This result is partially confirmed by Harris that studied the correlates and characteristics of boredom proneness and boredom (Harris, 2000). Proneness to boredom has been reported to be strongly associated with low academic performance, substance abuse problems, delinquency and high user technologies (Amos, Wiltshire, Haw, \& McNeill, 2006; Pekrun, Hall, Goetz, \& Perry, 2014; Thackray, 1981).

Data from Study were used to provide initial evidence on the validity of the five BPS dimensions related to deviances. In these analyses the five dimensions were entered simultaneously with age and the other demographic data collected. Data show as young people are affected particularly by boredom. Time problems are the most frequent among the class aged $16-18$ and $18-21$ than the 25+. In this last group, obligations concerning work, career and family reduce the time available for boredom and deviant activities. Among youth, other problems might be relevant since studies have shown that boredom is a recurring problem among this group. The danger of becoming socially isolated exists in case of a loss of mobility (Haller, Hadler, \& Kaup 2013; Sundberg et al. 1991). To test the evidence above, it was decided to implement a model, in order to describe and analyze empirical phenomena it is appropriate to introduce a statistical relationship, since it is not possible to know an exact relationship between variables. The linear model developed can be expressed as Equation (1):

$$
Y=\beta_{0}+\beta_{1} X_{1}+\beta_{2} X_{2}+\cdots+\beta_{k} X_{K}+\varepsilon
$$

where $\beta_{0}, \beta_{1}, \ldots, \beta_{k}$ are the coefficients and $X_{1}, X_{2}, \ldots, X_{k}$ variables that influence the responsive $(\mathrm{Y})$. In detail, $\beta_{0}$ represents $\mathrm{Y}$ (boredom) value when the variables are null, while $\beta_{j}$ coefficients (with $j=1,2,3, \ldots, k$ ) express corresponding Y variation to a unit increase of $X_{j}$ fixing the other variables. Verification of statistics and regressors goodness can be applied, within multiple linear regression, through $\mathrm{R}^{2}$ (correct) for the model as a whole and with $\mathrm{p}$-value for model's individual predictors.

Information in Table 1 shows a significant link between Boredom and the other covariates selected. In detail, model expresses a negative relationship between boredom and: sport player $(-0.3804)$, education level $(-0.8738)$, leisure activities $(-0.4992)$; instead a strongly positive relationship emerges with deviance activities $(+0.6762)$ and social network using $(+0.4910)$. Not statistically significant appear the aspects linked to city sizing and religious orientation. 
Table 1. Covariates analyzed.

\begin{tabular}{ccc}
\hline Covariates & Covariates & Standard Error $(\varepsilon)$ \\
\hline Income & $-0.0367^{* *}$ & 0.0493 \\
Social Network User & $0.4910^{* *}$ & 0.4235 \\
Deviance Activities & $0.6762^{* *}$ & 0.0378 \\
Sport Player & $-0.3804^{*}$ & 0.0553 \\
Education Level & $-0.8738^{* *}$ & 0.0026 \\
Religious & -0.4612 & 0.8251 \\
Town Size & $-0.0358^{* *}$ & 0.0578 \\
Leisure Activities & $-0.4992^{*}$ & 0.0127 \\
\hline
\end{tabular}

${ }^{* *} p<0.05 ;{ }^{*} p<0.01$; Corrected $\mathrm{R}^{2}: 0.769093517$.

\section{Conclusion and Limitation}

Relatively little research has focused on the characteristics of boredom and deviant behavior activities. According with the purpose, this study provided primary evidence of an interaction between boredom and some of its drivers, in order to implement action at institutional level to prevent form of social deviancies. Subjects with a high level of boredom resistance show a low interest in social deviance activities, because they have higher capacity to self-entertain compared with the other one. Consistent with our expectations, expressed above, daytime activities and boredom proneness scores were found to be significant predictors of youth deviance. Our findings suggest that it may be beneficial to devote more attention to identifying (and assisting) individuals who, for whatever reasons, have a propensity for boredom that could degenerate into social isolation activities and deviance activities. Depending on the reasons for their "type of boredom", such individuals could be helped through various interventions or by altering various aspects of the daily activities/job. The significant and positive relationships found in the present study between boredom and the variable selected, it is also congruent with various definitions of boredom describe in literature.

Nevertheless, the current study was not without limitations. Last and most importantly, behavioral researchers rarely rely on true population sampling to make the case for generalizability (Highhouse \& Gillespie, 2009). Nonetheless, we urge future research to include a wide sample and triangulate our study results.

As a final limitation, we used self-report weight and height in lieu of assessing these variables objectively. These may not be very accurate because people tend to overestimate or underestimate the aspect of their inner self (Connor Gorber, Tremblay, Moher, \& Gorber, 2007). In future, it would be ideal for researchers to directly measure these variables.

Considering both the benefits and limitations of our research, the current study should be considered to be a first step in demonstrating the value of 
pro-active policies to reduce deviant behavior, and we believe it is a necessary first step.

\section{Acknowledgements}

I would like to show my warm thanks to Dr. Dinicolo Guglielmo L.M. ( $\mathrm{PhD}$ University of Enna "Kore", Enna, Italy) for collaboration in collecting data and the statistical elaboration draw in this paper.

\section{References}

Agnew, R. (1992). Foundation for a General Strain Theory of Crime and Delinquency. Criminology, 30, 47-87. https://doi.org/10.1111/j.1745-9125.1992.tb01093.x

Ahmed, S. M. S. (1990). Psychometric Properties of the Boredom Proneness Scale. Perceptual and Motor Skills, 71, 963-966. https://doi.org/10.2466/pms.1990.71.3.963

Amos, A., Wiltshire, S., Haw, S., \& McNeill, A. (2006). Ambivalence and Uncertainty: Experiences of and Attitudes toward Addiction and Smoking Cessation in the Mid-to-Late Teens. Health Education Research, 21, 181-191.

https://doi.org/10.1093/her/cyh054

Baldwin, J. D. (1985). Thrill and Adventure Seeking and the Age Distribution of Crime: Comment on Hirschi and Gottfredson. American Journal of Sociology, 90, 1326-1330. https://doi.org/10.1086/228212

Barbalet, J. M. (1999). Boredom and Social Meaning. British Journal of Sociology, 50, 631-646. https://doi.org/10.1080/000713199358572

Berlyne, D. E. (1950). Novelty and Curiosity as Determinants of Exploratory Behavior. British Journal of Psychology, 41, 68-80.

Blunt, A., \& Pychyl, T. A. (1998). Volitional Action and Inaction in the Lives of Undergraduate students: State Orientation, Procrastination and Proneness to Boredom. Personality and Individual Differences, 24, 837-846. https://doi.org/10.1016/S0191-8869(98)00018-X

Brissett, D., \& Snow, R. P. (1993). Boredom: Where the Future Isn't. Symbolic Interaction, 16, 237-256. https://doi.org/10.1525/si.1993.16.3.237

Caffray, C. M., \& Schneider, S. L. (2000). Why Do They Do It? Affective Motivators in Adolescents' Decisions to Participate in Risk Behaviours. Cognition and Emotion, 14, 543-576. https://doi.org/10.1080/026999300402790

Caliman, G. (1997). Normalità devianza, lavoro. Roma, LAS: Giovani a Belo Horizonte.

Clinard, M. B., \& Meier, R. F. (1995). Sociology of Deviant Behaviour (9th ed.). Orlando, FL: Harcourt Brace College Publishers; Holt, Rinehart and Winston, Inc.

Cloward, R. A., \& Ohlin, L. E. (1960). Deliquency and Opportunity: A Theory of Deliquent Gangs. Glencoe: Free Press.

Cohen, A. K. (1955). Delinquent Boys. The Culture of the Gang. Glencoe. IL: Free Press.

Cohen, P. (1972). Sub-Cultural Conflict and Working Class Community. Working Papers in Cultural Studies 2, Birmingham: University of Birmingham.

Connor Gorber, S., Tremblay, M., Moher, D., \& Gorber, B. (2007). A Comparison of Direct vs. Self-Report Measures for Assessing Height, Weight and Body Mass Index: A Systematic Review. Obesity Reviews, 8, 307-326.

https://doi.org/10.1111/j.1467-789X.2007.00347.x

Cook, M. (1993). Levels of Personality (2nd ed.). London: Cassell Publishers Ltd. 
Durkheim, E. (1962). La divisione del lavoro sociale (Parigi 1893). Milano: Libro III.

Durkheim, E. (2008). Il suicidio. L'educazione morale. Torino: Utet.

Edwards, W. S., \& Cantor, D. (1991). Towards a Response Model in Establishment Surveys. In Measurement Errors in Surveys (pp. 211-233). New York, NY: Wiley.

Farmer, R. D., \& Sundberg, N. (1986). Boredom Proneness: The Development and Correlates of a New Scale. Journal of Personality Assessment, 50, 4-17. https://doi.org/10.1207/s15327752jpa5001_2

Gana, K., \& Akremi, M. (1998). French Adaptation and Validation of the Boredom Proneness Scale (BP). L'Annee Psychologique, 98, 429-450. https://doi.org/10.3406/psy.1998.28576

Garfinkel, H. (1967). Studies in Ethnomethodology. Cambridge: Polity Press.

Gibbons, D. C., \& Kronn, M. D. (1991). Delinquent Behavior (5th ed.). Upper Saddle River, NJ: Prentice Hall.

Giddens, A. (1991). Modernity and Self-Identity. Palo Alto, CA: Stanford University Press.

Gordon, W. R., \& Caltabiano, M. L. (1996). Urban-Rural Differences in Adolescent Self-Esteem, Leisure Boredom, and Sensation Seeking as Predictors of Leisure Time Usage and Satisfaction. Adolescence, 31, 881-901.

Haller, M., Hadler, M., \& Kaup, G. (2013). Leisure Time in Modern Societies: A New Source of Boredom and Stress? Social Indicators Research: An International and Interdisciplinary Journal for Quality-of-Life Measurement, 111, 403-434.

https://doi.org/10.1007/s11205-012-0023-y

Harris, M. B. (2000). Correlates and Characteristics of Boredom Proneness and Boredom. Journal of Applied Social Psychology, 30, 576-598. https://doi.org/10.1111/j.1559-1816.2000.tb02497.x

Highhouse, S., \& Gillespie, J. Z. (2009). Do Samples Really Matter That Much? In C. E. Lance, \& R. J. Vanderberg (Eds.), Statistical and Methodological Myths and Urban Legends: Doctrine, Verity and Fable in the Organizational and Social Sciences (pp. 247-265). Abingdon: Routledge/Taylor \& Francis Group.

Hirschi, T. (1969). Causes of Delinquency. Berkeley, CA: University of California Press.

Hirschi, T., \& Gottfredson, M. (1993). Testing the General-Theory of Crime-Commentary. Journal of Research in Crime and Delinquency, 30, 47-54. https://doi.org/10.1177/0022427893030001004

Iso-Ahola, S. E., \& Crowley, B. D. (1991). Adolescent Substance Abuse and Leisure Boredom. Journal of Leisure Research, 23, 260-271.

Kemper, T. (1978). A Social Interactional Theory of Emotion. New York, NY: Wiley.

Klapp, O. E. (1986). Overload and Boredom: Essays on the Quality of Life in the Information Societv. Westport, CT: Greenwood Press.

Lea, J., \& Young, J. (1984). What Is to Be Done about Law and Order-Crisis in the Eighties. Harmondsworth: Penguin.

Luhmann, N. (1984). Soziale Systeme: Grundriss einer allgemeinen Theorie, Suhrkamp, Frankfurt am Main. trad. it. Sistemi sociali: Fondamenti di una teoria generale, Bologna: Il Mulino, 1990.

Marx, K. (2004). Manoscritti Economico-filosofici del 1844. (a cura di) N. Bobbio, Einaudi.

Mason, B. (1996). From Shamans to Shaming: A History of Criminological Thought. In K. M. Hazelhurst (Eds.), Crime and Justice: An Australian Textbook in Criminology 
(pp. 13-37). Sydney: LBC Information Services.

Mason, G. J., \& Wilson, P. (1988). Sport, Recreation and Juvenile Crime. Canberra: Institute of Criminology.

Matza, D. (1964). Delinquency and Drift. New York, NY: Jolm Wiley and Sons.

Merton, R. K. (1938). Social Structure and Anomie. American Sociological Review, 1, 672-682. https://doi.org/10.2307/2084686

Merton, R. K. (1967). On Theoretical Sociology: Five Essays, Old and New. New York, NY: Free Press.

Merton, R. K. (1968). Social Theory and Social Structure (Enlarged ed.). New York, NY: The Free Press.

Myers, A. K., \& Miller, N. E. (1954). Failure to Find a Learned Drive Based on Hunger; Evidence for Learning Motivated by "Exploration". Journal of Comparative and Physiological Psychology, 47, 428-436. https://doi.org/10.1037/h0062664

Pekrun, R., Hall, N. C., Goetz, T., \& Perry, R. P. (2014). Boredom and Academic Achievement: Testing a Model of Reciprocal Causation. Journal of Educational Psychology, 106, 696-710. https://doi.org/10.1037/a0036006

Ragheb, M. G., \& Merydith, S. P. (2001). Development and Validation of a Multidimensional Scale Measuring Free Time Boredom. Leisure Studies, 20, 41-59. https://doi.org/10.1080/02614360122569

Schafer, W. E. (1969). Some Sources and Consequences of Interscholastic Athletics: The Case of Participation and Delinquency. International Review of Sport Sociology, 4, 63-79. https://doi.org/10.1177/101269026900400104

Seamon, J. G., \& Kenrick, D. T. (1994). Psychology (2nd ed.). Englewood Cliffs, NJ: Prentice-Hall.

Seeman, M. (1959). On the Meaning of Alienation. American Sociological Review, 24, 783-791. https://doi.org/10.2307/2088565

Seib, H. M., \& Vodanovich, S. J. (1998). Cognitive Correlates of Boredom Proneness: The Role of Private Self-Consciousness and Absorption. The Journal of Psychology: Interdisciplinary and Applied, 132, 642-652. https://doi.org/10.1080/00223989809599295

Segrave, J., \& Halstad, D. (1984). Interscholastic Athletic Participation and Delinquent Behavior: An Empirical Assessment of Relavant Variables. Sociology of Sport Journal, 1, 117-137. https://doi.org/10.1123/ssj.1.2.117

Simmel, G. (1996). Le metropoli e la vita dello spirito. a cura di P. Jedlowski, Armando Editore.

Stebbins, R. A. (2002). Choice in Experiential Definitions of Leisure. Leisure Studies Association Newsletter, 63, 18-20.

Stein, R. T., \& Heller, T. (1979). An Empirical Analysis of the Correlations between Leadership Status and Participation Rates Reported in the Literature. Journal of Personality and Social Psychology, 37, 1993-2002. https://doi.org/10.1037/0022-3514.37.11.1993

Sudman, S., Willimack, D. K., Nichols, E., \& Mesenbourg, T. L. (2000). Exploratory Research at the U.S. Census Bureau on the Survey Response Process in Large Companies. In Proceedings of the 2nd International Conference on Establishment Surveys (pp. 327-337). Boston, MA: American Statistical Association.

Sundberg, N. D., Latkin, C. A., Farmer, R., \& Saoud, J. (1991). Boredom in Young Adults: Gender and Cultural Comparisons. Journal of Cross-Cultural Psychology, 22, 209-223. https://doi.org/10.1177/0022022191222003

Thackray, R. I. (1981). The Stress of Boredom and Monotony: A Consideration of the 
Evidence. Psychosomatic Medicine, 43, 165-176.

https://doi.org/10.1097/00006842-198104000-00008

Trojanowicz, R. C., \& Morash, M. (1992). Juvenile Delinquency: Concepts and Control (5th ed.). Englewood Cliffs, NJ: Prentice-Hall, Inc.

Vodanovich, S. J., \& Kass, S. J. (1990a). A Factor Analytic Study of the Boredom Proneness Scale. Journal of Personality Assessment, 55, 115-123. https://doi.org/10.1080/00223891.1990.9674051

Vodanovich, S. J., \& Kass, S. J. (1990b). Age and Gender Differences in Boredom Proneness. Journal of Social Behavior and Personality, 5, 297-307.

Vodanovich, S. J., Wallace, J. C., \& Kass, S. J. (2005). A Confirmatory Approach to the Factor Structure of the Boredom Proneness Scale: Evidence for a Two-Factor Short Form. Journal of Personality Assessment, 85, 295-303. https://doi.org/10.1207/s15327752jpa8503_05

Volkart, H. (1951). Social Behavior and Personality. Contributions of W.I. Thomas to Theory and Social Research, New York, NY: Social Science Research Council.

Weber, M. (1920). Sociologia delle religioni. Ghibli, 2015.

White, R. W. (1959). Motivation Reconsidered: The Concept of Competence. Psychological Review, 66, 297-333. https://doi.org/10.1037/h0040934

Wilmott, P. (1966). Adolescent Boys of East London. London: Routledge and Kegan Paul.

Wilson, J. Q., \& Herrnstein, R. J. (1998). Crime \& Human Nature: The Definitive Study of the Causes of Crime. New York, NY: Simon and Schuster.

Wink, P., \& Donahue, K. (1997). The Relation between Two Types of Narcissism and Boredom. Journal of Research in Personality, 31, 136-140. https://doi.org/10.1006/jrpe.1997.2176

Zuckerman, M., Eysenck, S. B., \& Eysenck, H. J. (1978). Sensation Seeking in England and America: Cross-Cultural, Age, and Sex Comparisons. Journal of Consulting and Clinical Psychology, 46, 139-149. https://doi.org/10.1037/0022-006X.46.1.139 